\title{
High-tech clusters, technology spillovers, and trade secret laws
}

\author{
Andrea Fosfuri ${ }^{\mathrm{a}, \mathrm{b}, *}$, Thomas Rønde $\mathrm{e}^{\mathrm{b}, \mathrm{c}, \mathrm{d}}$ \\ a Departamento de Economía de la Empresa, Universidad Carlos III de Madrid, Calle Madrid, \\ 126, 28903 Getafe, Madrid, Spain \\ ${ }^{\mathrm{b}}$ C.E.P.R., London, UK \\ ${ }^{\mathrm{c}}$ University of Copenhagen, Copenhagen, Denmark \\ ${ }^{\mathrm{d}}$ C.E.B.R., Copenhagen, Denmark
}

\begin{abstract}
We analyze firms' incentives to cluster in an industrial district to benefit from reciprocal technology spillovers. A simple model of cumulative innovation is presented, where technology spillovers arise endogenously through labor mobility. It is shown that firms' incentives to cluster are the strongest when the following three conditions are met: (1) the growth potential of an industry is high; (2) competition in the product market is relatively soft; (3) the probability of a single firm to develop an innovation is neither very high nor very low. Trade secret protection based on punitive damages is, except in some extreme cases, beneficial for firms' profits, stimulates clustering, and is not an impediment to technology spillovers.
\end{abstract}

JEL classification: J3; K2; L1; O32; O34

Keywords: Cumulative innovation; Industrial districts; Intellectual property rights; Technology spillovers

\section{Introduction}

During the 1980s and the 1990s, Silicon Valley has been the prototypical example of a successful industrial district. In the mid-1990s, it was home to $20 \%$ of the world's largest technology companies (Businessweek, 25 August 1997), and the mean income was 50\%

* Corresponding author. Departamento de Economía de la Empresa, Universidad Carlos III de Madrid, Calle Madrid, 126, 28903 Getafe, Madrid, Spain. Tel.: +34-91-624-93-51; fax: +34-91-624-96-07.

E-mail addresses: fosfuri@emp.uc3m.es (A. Fosfuri), Thomas.Ronde@econ.ku.dk (T. Rønde). 
from complete. ${ }^{5}$ The first obstacle facing any firm alleging a misappropriation of a trade secret is to demonstrate that a trade secret exists. This often proves to be difficult as the information constituting a trade secret is unknown to the public and may not be easily defined. ${ }^{6}$ The alleging firm's position is particularly weak in cases concerning employees defecting to competitors. Courts are concerned about employees' freedom to seek new job opportunities. They are thus reluctant to prevent an employee from working for a competitor by granting injunctive relief or enforcing a very restrictive non-compete covenant. Hyde and Gilson argue that trade secret protection is particularly weak in California and that this explains the high labor turnover in Silicon Valley. However, both the cultural and the legal explanations of the high labor turnover seem to forget that firms have monetary instruments to keep their employees: they might simply pay a higher wage in order to avoid turnover and constrain the outward knowledge flow.

In this paper, we build a simple model that offers an economic rationale to the empirical evidence discussed above. An entrepreneur (a firm) needs a researcher (a worker) to run his R\&D department. An important ingredient of our model is that knowledge and innovation are cumulative. The R\&D activity gives rise to knowledge, which is valuable both for directly commercializing a product (first generation) and for being the basis for a new and better version of the product (second generation). We follow Pakes and Nitzan (1983) and endogenize technology spillovers through labor mobility. After having successfully developed the first-generation product, the worker can move to a rival firm, enabling it to use the knowledge embedded in the product. The movement of the worker contributes to make the knowledge widespread at the industry level, thereby rising the likelihood that the second-generation product will be developed. We explicitly consider the competition for the services of the worker, and technology spillovers arise only if the rival firm is willing to offer a higher wage to the worker than the current employer.

We then move a step backwards in the game tree and allow firms to choose locations. Each firm can either decide to locate in a separate region or to 'cluster' in the same area as the rival. In our model, technology spillovers are the only reason for firms to cluster. Put differently, technology spillovers are a necessary condition for firms to cluster. However, technology spillovers are not a sufficient condition, because workers earn a higher expected wage when firms locate together. In equilibrium, firms cluster only if the expected benefits from technology spillovers outweigh the additional wage bill.

We identify three conditions that increase the benefits from technology spillovers and strengthen firms' incentives to cluster. First, product market competition is soft, so the additional competition due to technology spillovers does not dissipate too much rent. Second, the probability of a single firm to develop the second-generation product is neither very small nor very large. Third, the value of the second-generation product is high relative

\footnotetext{
5 The discussion here is based on trade secret protection in the US under the Uniform Trade Secrets Act (see, e.g., Choate et al., 1987; Budden, 1996). The laws of trade secrets build on the same principles in most countries, so the problems sketched here are also present outside the US.

6 Some trade secrets such as a formula or a customer list can be easily identified. However, many trade secrets have an element of tacit knowledge, and it is hard to draw the line between the general knowledge that an employee has received through his education, background, and work experience, and the specific knowledge that he has received from an employer and that one could classify as a trade secret.
} 
to the first. These last two conditions ensure that the benefits of having one more firm trying to develop the second-generation product are high.

Finally, we use our framework to analyze how trade secret protection affects both the decision to cluster and the intensity of labor mobility. We show that a system of trade secret protection based on punitive damages, except in some extreme cases, increases profits, stimulates clustering, and is not an impediment to technology spillovers. Trade secret protection that prevents technology spillovers from arising (post-employment covenants not to compete, injunctive relief, or excessive damages) does not induce clustering and reduces profits.

Technology spillovers and high-tech clusters have received attention both from industrial economists and economic geographers. Katz (1986), Kamien et al. (1992), and Choi (1993) have studied the relationship between technology spillovers and research joint ventures (RJVs). An RJV allows firms to coordinate their R\&D investments and to share the R\&D outcomes. There is, therefore, a parallelism between RJVs and high-tech clusters. Indeed, joining a cluster can be seen as a way for firms to share knowledge in circumstances in which more efficient contractual arrangements such as licensing, RJVs, or patent pooling are not available. An important difference with respect to our work is that the literature on RJVs does not elucidate the mechanism through which such spillovers take place and, typically, treats technology spillovers as exogenous. ${ }^{7}$

More recently, some authors have recognized that an important source of technology spillovers is labor mobility. Following Pakes and Nitzan (1983), this literature has treated technology spillovers as endogenous: firms actively try to prevent workers from leaving and to 'poach' workers from competitors. In this vein, Fosfuri et al. (2001) analyze technology spillovers due to workers' mobility from multinationals to local firms, and Gersbach and Schmutzler (2003) study how the presence of endogenous spillovers affects the incentives to invest in cost-reducing innovations. Related to this, there has been some work on how firms can design their organization in order to avoid that valuable knowledge spills over to competitors through workers' mobility. See, e.g., Rajan and Zingales (2001), Rønde (2001), and Zabojnik (2002).

There are two recent papers that study the functioning of industrial clusters when technology spillovers arise through labor mobility, but focus on issues complementary to the ones analyzed in this paper. Cooper (2001) looks at firms' and workers' investment in R\&D and human capital, respectively, an aspect that we discuss briefly in an extension. However, he abstracts from the strategic interaction between the labor and the product markets, which plays a crucial role in our model, and does not consider the location choice of firms. Combes and Duranton (2001) use, as we do, the model introduced by Pakes and Nitzan (1983) as a building block. There are, however, a number of differences between their and our work. Most importantly, we focus on cumulative innovations and trade secret laws, whereas Combes and Duranton consider the interaction between product differentiation and the 'absorptive capacity' of firms.

Our paper is also related to the literature on patents and cumulative R\&D (Scotchmer, 1991). This literature has primarily looked at the role of patents in providing adequate

\footnotetext{
7 Mai and Peng (1999) use such 'black-box' type of spillovers to study firms' incentives to cluster.
} 
incentives to sequential innovators. Little attention has been placed on the importance of technology spillovers. A recent exception is Bessen and Maskin (2000), who present a simple model of cumulative R\&D and ask the question of whether stronger patent protection leads to more or to less innovation. The analysis of patent protection is different from that of trade secret protection, ${ }^{8}$ but Bessen and Maskin also reach the conclusion that very strong protection of intellectual property may slow down innovation and reduce overall welfare.

The rest of the paper is organized as follows. The next section describes the basic model, and Section 3 derives the theoretical relationship between technology spillovers, labor mobility and clustering. Section 4 discusses some extensions of our basic model, and Section 5 concludes the paper.

\section{The model}

\subsection{The first period}

Consider a world where there are two periods and two entrepreneurs each running a firm. Denote the two firms as A and B. At the beginning of the game, firms must choose irrevocably their locations. The firms can either decide to locate in separate regions or to cluster in the same area. The firms have no marketable product at this stage. After locating, each firm hires a researcher (a worker) to develop a product. The worker is hired from a pool of identical workers. Workers have a reservation wage $\bar{w}$, which is normalized to zero. Workers are wealth constrained and cannot borrow on the financial markets, so the firstperiod wage must be nonnegative.

We assume that each firm undertakes a costless R\&D project that has an exogenous probability $s$ of succeeding. We relax this assumption in Section 4 where the probability of success is endogenized. The successes of the two firms' R\&D projects are independently distributed. A successful project leads to an innovation that we denote as innovation 1 . With probability $(1-s)$ the project is unsuccessful, and the firm stays out of the market in the first period. Once the innovation process is resolved, production takes place, the good is sold, and first-period profits are realized. The value of exploiting innovation 1 as a monopolist is $\pi_{1}$. If both firms develop the innovation, the duopoly profits are $\alpha \pi_{1}$. The parameter $\alpha$ measures the degree of product market competition, with lower values of $\alpha$ associated with tougher competition. We assume that $\alpha \in[0,1 / 2]$.

\subsection{The second period}

In the second period, firms have the possibility to develop a new and better version of the product (innovation 2), but only if they have access to the knowledge created

\footnotetext{
8 Most notably, a patent assigns an exclusive right to its holder, whereas trade secret laws do not protect against independent, although identical, innovations by other firms.
} 
when developing innovation 1 . R\&D is therefore cumulative. This knowledge also allows firms to exploit innovation 1 in the second period if they fail to develop innovation 2 . We assume again that $\mathrm{R} \& \mathrm{D}$ is costless and that the probability of success is $s$ (conditional on having the necessary knowledge) and is independently distributed across firms. Innovation 2 is drastic with respect to innovation 1. Hence, a firm endowed with innovation 2 earns monopoly profits both when the rival has innovation 1 and when it has no product at all. Monopoly profits of exploiting innovation 2 are $\pi_{2}$, whereas duopoly profits are $\alpha \pi_{2}$.

We make two simplifying assumptions concerning the knowledge created in the first period. First, after developing innovation 1, the entrepreneur and the worker have all the relevant information. Therefore, if the worker employed in the first period leaves, the entrepreneur can instruct another worker and continue the R\&D activity uninterruptedly. Second, if the two firms have experienced the same R\&D outcome in the first period (either success or failure), they have the same knowledge and have no gains from acquiring each other's knowledge. Notice that a worker possesses valuable knowledge if he has worked for the only successful firm in period 1 . In all other states of the world, workers are simply paid the reservation wage.

The outcome of the second period depends on the results of the R\&D activities in the first period. We will therefore describe the game in the second period for the different possible states of the world.

No firm has developed innovation 1. The firms start all over again, and everything is as in period 1 except that firms do not choose location.

Both firms have developed innovation 1 . The two firms aim at developing innovation 2. A firm earns $\pi_{2}$ if it is the only one to develop innovation 2 , whereas the rival earns 0 . The firms earn $\alpha \pi_{2}$ if they both succeed and $\alpha \pi_{1}$ if they both fail.

Only one firm has developed innovation 1. Assume that firm A has developed innovation 1 and firm B has not (the other case is analogous). Firm B would like to hire the employee of firm A to acquire the knowledge necessary to develop innovation $2 .{ }^{9} \mathrm{We}$ assume that this is only feasible when firms are located in the same region, for instance, because relocation costs or informational costs of identifying the 'right' worker are large across regions. This assumption is relaxed in Section 4. We need to consider the two subgames where the firms are in the same region and in separate regions.

Suppose that the firms have chosen separate locations. Firm A tries to develop innovation 2 and firm B innovation 1. Firm A drives firm B out of the market if it is successful and earns $\pi_{2}$. If firm A fails, but firm B succeeds, both firms earn $\alpha \pi_{1}$. Finally, if both firms fail, firm A earns $\pi_{1}$ and firm B earns 0 .

Suppose instead that the firms have chosen a joint location. At the beginning of the second period, firm B tries to hire the worker that was employed by firm A in the first period. Obviously, firm A would like to retain the worker in order to have a head start in the second period and can take different legal actions to achieve this goal. Foreseeing that the worker may leave, firm A can include a covenant not to compete in the worker's

${ }^{9}$ We disregard licensing contracts, as it is very difficult to license nonpatented information (Arrow, 1962; Cheung, 1982). 


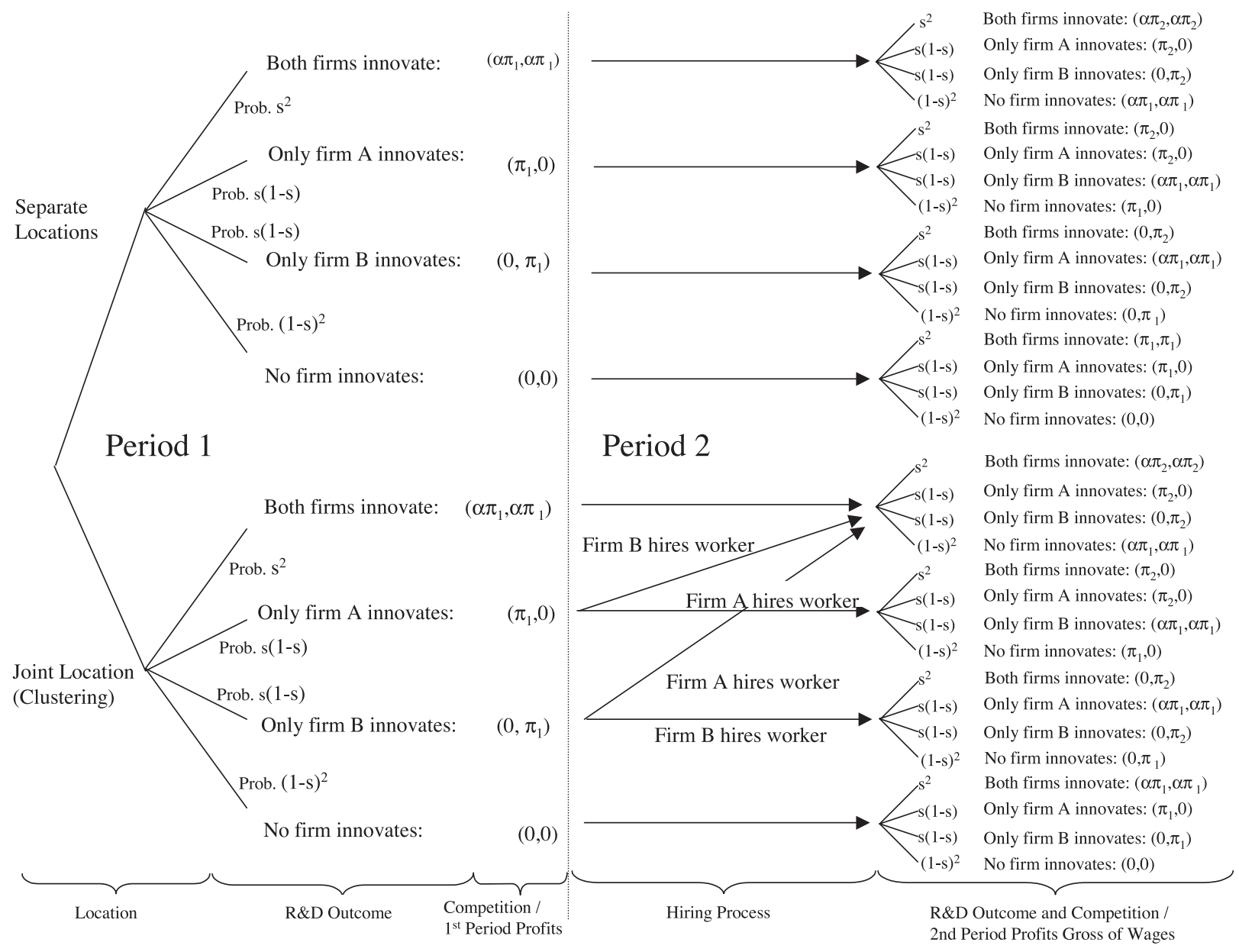

Fig. 1. An illustration of the game with all the different states of the world and the choices of the firms. 
employment contract that prevents him from working for firm B in the second period. Another possibility is to sue firm B after the worker has left. The relative effectiveness of these measures depends on the jurisdiction and the nature of the innovation (see the Introduction). We consider primarily the possibility to go to court and assume that if a worker brings valuable knowledge to a rival, the hiring firm has to pay (expected) damages of $D, D \in[0, \infty]{ }^{10}$ This reflects the situation in Silicon Valley where covenants not to compete are very seldom enforced (see Gilson, 1999). ${ }^{11}$

We model the competition for the worker in the following way. Each firm simultaneously and independently makes a take-it-or-leave-it offer to the worker. The firm who offers more hires the worker and pays the wage that it has offered. Put differently, the hiring process works like a first-price auction. If both firms offer the same wage, we assume that the firm whose valuation of the worker is highest hires him. The tie-breaking rule ensures that an equilibrium in pure strategies exists. We will focus on the equilibrium in which the firm hiring the worker pays exactly the rival's valuation. ${ }^{12}$ Each firm's valuation of the worker depends on its outside options that we will derive later.

If firm A retains the worker, the game continues as in the subgame where the firms are in separate locations. If firm B hires the worker, the game continues as in the state where both firms have developed innovation 1 in the first period.

Fig. 1 illustrates the game with all the possible states of the world and the actions taken.

\section{Solving the model}

We are now ready to solve the game. Let us start by computing each firm's expected profits if they locate in separate regions. Notice that in this case, there is no possibility of labor mobility, so technology spillovers cannot arise. We proceed by backward induction.

Let $V_{i j}$ be firm $i$ 's expected profits before the second innovation round is resolved. $V_{i j}$ is a function of the firm's knowledge (subscript $i$ ) and the rival's knowledge (subscript $j$ ),

\footnotetext{
10 Notice that if expected damages are sufficiently high, this is equivalent to strong enforcement of covenants not to compete, because an outside firm would never find it profitable to obtain trade secrets by poaching a worker. We discuss briefly the case of covenants not to compete in Section 4.

11 Even if the courts of California are reluctant to enforce trade secret laws in cases that involve misappropriation by former employees, there have been several law suits that made headlines in the business press: in 1994; Vermont Microsystems was awarded \$25.5 million in damages, because Autodesk was found to have used trade secrets brought by a former employee; in 2000; Intel accused Broadcom for 'poaching' key employees to acquire its communications-chip technology and sued for damages and injunctive relief (the case was settled out of court); in 2001, Avant was ordered to pay $\$ 182$ million plus interest to Cadence Design Systems for having marketed products partly based on source code obtained from a former employee.

12 We disregard equilibria where both firms offer a wage between the lowest and the highest valuation of the worker (and where the firm with the highest valuation hires him), since in these equilibria the firm with the lowest valuation is playing a weakly dominated strategy.
} 
with $i, j \in\{0,1\}$ where 1 indicates that the firm in question possesses the knowledge of the first innovation, and 0 indicates that it does not. There are four possible states of nature: both firms have the knowledge, no firm has the knowledge, only firm A or only firm B has the knowledge. Expected profits are

$$
\begin{aligned}
& V_{11}=s^{2} \alpha \pi_{2}+s(1-s) \pi_{2}+(1-s)^{2} \alpha \pi_{1}, \\
& V_{00}=s^{2} \alpha \pi_{1}+s(1-s) \pi_{1}, \\
& V_{10}=s \pi_{2}+(1-s) s \alpha \pi_{1}+(1-s)^{2} \pi_{1}, \\
& V_{01}=s(1-s) \alpha \pi_{1},
\end{aligned}
$$

where $V_{10}>V_{11}>V_{00}>V_{01}$ as long as $\pi_{2}>\pi_{1}$.

The per firm expected profits at time $t=0$ if firms locate separately are therefore:

$$
\prod_{\text {sep }}=s^{2}\left[\alpha \pi_{1}+V_{11}\right]+s(1-s)\left[\pi_{1}+V_{10}+V_{01}\right]+(1-s)^{2} V_{00} .
$$

We now focus on the other branch of the game tree in which firms decide to cluster at $t=0$. As above, we proceed by backward induction.

Let us consider the hiring process. Recall that this plays a role only in asymmetric situations. For simplicity of exposition, let us say that firm A has got innovation 1 and firm $\mathrm{B}$ has not. Firm A will earn $V_{10}$ if it keeps the worker, and $V_{11}+D$ if it loses him to firm B, since it will receive damages. Therefore, firm A's valuation of the worker is $v_{\mathrm{A}}=\operatorname{Max}\left\{V_{10}-V_{11}-D, 0\right\}$. Firm B will earn $V_{11}-D$ if it is successful in poaching the worker, and $V_{01}$ if it is not. Firm B's valuation of the worker is $v_{\mathrm{B}}=\operatorname{Max}\left\{V_{11}-D-V_{01}, 0\right\}$. We focus primarily on the case where for both firms the expected damages do not exceed the value of the worker.

A.1. $D \leq \operatorname{Min}\left\{V_{11}-V_{01}, V_{10}-V_{11}\right\}$ (trade secret protection is not excessive).

Two situations are possible: either $v_{\mathrm{A}} \geq v_{\mathrm{B}}$, and firm A keeps the worker by paying him $w_{\mathrm{ns}}=V_{11}-D-V_{01}$; or $v_{\mathrm{A}}<v_{\mathrm{B}}$, and firm $\mathrm{B}$ hires the worker by paying $\operatorname{him} w_{\mathrm{s}}=V_{10}-V_{11}-D$. In the latter case, technology spillovers arise since the knowledge becomes widespread across the industry. Notice that the worker in both cases will be paid more than the wage in the pool. A joint location increases the expected wage of the workers, because firms compete for the knowledge that the workers have accumulated in their prior jobs. However, stronger trade secret protection acts in the opposite direction by reducing the workers' expected wage.

The following result summarizes the outcome of the hiring process:

Lemma 1. Suppose that the firms are in a joint location, and only one firm has developed innovation 1 in the first period. Technology spillovers arise if and only if

$$
2 V_{11}>V_{10}+V_{01} \text {. }
$$


Proof. The worker moves if $v_{\mathrm{A}}<v_{\mathrm{B}}$. After substituting, this gives the condition reported above.

Lemma 1 says that the worker moves only if this increases expected industry profits. Notice that the strength of trade secret protection does not affect the technology spillover condition. As long as trade secret protection is not excessive, it increases the profits of the innovating firm by $D$ and decreases the wage of the worker by the same amount, but it does not prevent technology spillovers from occurring.

One can rewrite condition (3) as follows:

$$
\Delta E\left(\pi_{1}\right)+\Delta E\left(\pi_{2}\right)>0
$$

where $\Delta E\left(\pi_{1}\right)=-\left[(1-s)^{2}(1-2 \alpha)+2 s \alpha(1-s)\right] \pi_{1}$ and $\Delta E\left(\pi_{2}\right)=\left[s(1-s)-s^{2}(1-2 \alpha)\right] \pi_{2}$ are the changes in the expected industry profits accruing from innovation 1 and innovation 2 , respectively, due to technology spillovers.

First, notice that $\Delta E\left(\pi_{1}\right)<0$ since technology spillovers both increase the probability that innovation 1 will be replaced by innovation 2 and the probability that firms will end up competing with the first-generation product. In turn, this implies that

Remark 1. A necessary condition for technology spillovers to arise is $\Delta E\left(\pi_{2}\right)>0$, i.e., $(1-\alpha) s<1 / 2$.

In words, the probability to develop an innovation must be sufficiently low and/or competition sufficiently soft.

It is also useful to state the following remark:

Remark 2. A necessary condition for technology spillovers to arise is $\pi_{2}>\pi_{1}$.

Proof. Let $\pi_{2}=\pi_{1}$ (if $\pi_{2}<\pi_{1}$ the argument holds a fortiori). Then Eq. (3) implies that $1-2$ $(1-\alpha) s>(1-s)^{2}(1-2 \alpha) / s+2 \alpha(1-s)$. After some simplifications, one obtains that $(1-s) 3 s>1$, a contradiction.

One can decompose $\Delta E\left(\pi_{2}\right)$ in two parts, where $s(1-s) \pi_{2}>0$ captures the increase in expected industry profits due to an overall higher probability that innovation 2 is developed and $-s^{2}(1-2 \alpha) \pi_{2}<0$ is the reduction in expected industry profits due to increased competition (i.e., higher probability of a duopoly).

Summarizing, when the worker moves from firm A to firm B, two opposing effects occur to expected industry profits: (1) a positive effect due to the overall higher probability that the more valuable, second-generation product is developed; (2) a negative effect since firms will be more likely to compete with either the first- or the second-generation products.

The technology spillover condition, Eq. (3), is a function of $\alpha, s$, and $\pi_{2} / \pi_{1}$. We will refer to $\pi_{2} / \pi_{1}$ as the 'growth potential' of the industry, because it measures how profitable the second innovation is relative to the first. The following remark summarizes the comparative statics with respect to these parameters.

Remark 3. Technology spillovers arise for a larger parameter space if the growth potential of the industry is high, competition is soft, and the probability of innovating is intermediate. 
Proof. Let $\Phi \equiv(s /(1-s))\left(\pi_{2} / \pi_{1}\right)[1-2(1-\alpha) s]-(1-s)(1-2 \alpha)-2 s \alpha$. The proof follows from $\partial \Phi /\left(\partial\left(\pi_{2} / \pi_{1}\right)\right)>0$ and $\partial \Phi / \partial \alpha>0$ if the conditions in Remarks 1 and 2 are satisfied. Furthermore,

$$
\partial \Phi / \partial s>0(<0) \text { for } s<(>) \underline{s} \equiv 1-\sqrt{\frac{(1-2 \alpha) \frac{\pi_{2}}{\pi_{1}}}{1+2 \frac{\pi_{2}}{\pi_{1}}-2 \alpha\left(2+\frac{\pi_{2}}{\pi_{1}}\right)}}
$$

where $\underline{s} \in(0,1)$.

Let us first consider $\alpha$. Since there are less rents destroyed by competition if $\alpha$ increases, labor mobility is less of a threat to industry profits, and technology spillovers arise for a larger region of parameters, as Fig. 2 shows. Soft competition in the product market favors, therefore, technology spillovers. In a recent study on the adoption of manufacturing technologies by 1902 Canadian plants, Joung Yeo (2002) finds evidence in this direction by showing that technology spillovers are more likely when firms do not operate in the same product market.

Let us now consider $s$. Remember that technology spillovers have two opposing effects: increased competition and a higher overall probability to develop innovation 2. $s$ is important for both these effects, and we consider them in turn. First, starting from an asymmetric situation in the second period notice that when $s$ approaches either 0 or 1 , firms are very likely to end up competing on equal footing if technology spillovers take place, but very unlikely to be competing otherwise. Since competition destroys profits, this works against labor mobility. Hence, the parameter space under which technology spillovers take place expands for intermediate values of $s$. Second, and more important, technology spillovers increase the overall probability to develop innovation 2 by $s(1-s)$. Such marginal increment is maximized for $s=0.5$ and tends to 0 as $s$ approaches either 0 or 1 .

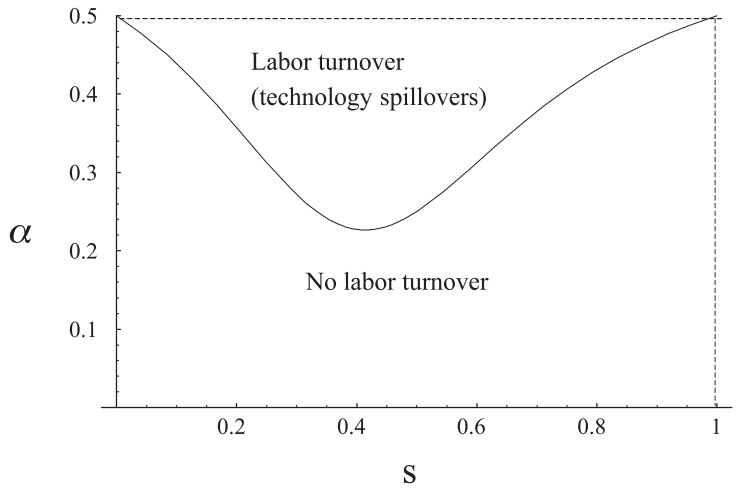

Fig. 2. The technology spillover condition as a function of $s$ and $\alpha\left(\pi_{2} / \pi_{1} \quad 2\right)$. The line indicates values of $s$ and $\alpha$ such that Eq. (3) holds with equality. Above the line, $v_{\mathrm{A}}<v_{\mathrm{B}}$ and technology spillovers occur. Below the line, $v_{\mathrm{A}} \geq v_{\mathrm{B}}$ and firm A keeps the worker in equilibrium. 


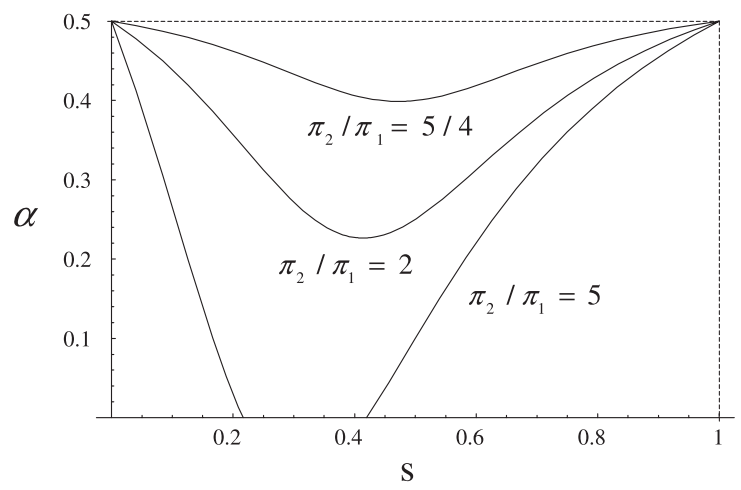

Fig. 3. The technology spillover condition for different values of $\pi_{2} / \pi_{1}$.

Again, the effect of a change in $s$ is non-monotonous, with the parameter space for which technology spillovers take place being the largest for intermediate values of $s$. Fig. 2 illustrates this point.

Fig. 3 shows the effect of increasing the growth potential of the industry, $\pi_{2} / \pi_{1}$. An increase in $\pi_{2} / \pi_{1}$ implies that it is more important in terms of expected industry profits that the second innovation is developed. This expands the region of parameters for which technology spillovers arise. Interesting enough, technology spillovers may occur even if competition among firms is extremely intense. Fig. 3 illustrates how technology spillovers may arise for $\alpha=0$ if $\pi_{2} / \pi_{1}$ is sufficiently high and $s<1 / 2$. This is worthwhile noting because previous theoretical analyses have found that the innovator retains the worker and technology spillovers do not take place if competition destroys industry profits (i.e., $\alpha<0.5$ ); see, for instance, Pakes and Nitzan (1983) and Fosfuri et al. (2001). What drives the difference between our results and the previous literature is the assumption of cumulative innovation. Indeed, if innovation is not cumulative, the only effect generated by technology spillovers is increased competition. This always reduces industry profits if $\alpha<0.5$.

This last finding is empirically important too, as it suggests that we are more likely to observe technology spillovers when later innovations have a much larger value than earlier ones. The prospect of future profits then outweighs the importance of actual profits. Hightech industries (telecommunications, semiconductors, software, biotechnology) that are typically associated with high rates of skilled labor mobility, seem to constitute an ideal test bed for our model. A somewhat different interpretation of this result is that we are more likely to observe technology spillovers when innovation 1 is based on basic knowledge with little commercial value, whereas innovation 2 is an application with a much larger market and value. ${ }^{13}$ Zucker and Darby (1996) and Zucker et al. (1998) document the importance of technology spillovers through the mobility of star scientists (i.e., highly productive individuals who discovered a major breakthrough) in the US biotechnology industry. Biotechnology is an industry par excellence where basic research plays a crucial

13 For instance, innovation 1 could be a research tool, which enables the development of innovation 2, but has no direct commercial value $\left(\begin{array}{ll}\pi_{1} & 0\end{array}\right)$. 
role. Similarly, Almeida and Kogut (1999) show that the localization of knowledge and the mobility of engineers are critical factors in semiconductors, another industry where basic research is important (for instance, advances in materials sciences are crucial in the search for new materials).

At this stage, we are now able to compute the expected profits of the firms when they decide to cluster. The expected profits depend on the result of the hiring process. Hence, we have

$$
\prod_{\text {clust }}=\left\{\begin{array}{l}
s^{2}\left(\alpha \pi_{1}+V_{11}\right)+s(1-s)\left(\pi_{1}+2 V_{11}-w_{s}\right)+(1-s)^{2} V_{00} \text { if } 2 V_{11} \geq V_{10}+V_{01}, \\
s^{2}\left(\alpha \pi_{1}+V_{11}\right)+s(1-s)\left(\pi_{1}+V_{10}+V_{01}-w_{\mathrm{ns}}\right)+(1-s)^{2} V_{00} \text { otherwise }
\end{array}\right.
$$

where $w_{\mathrm{s}}=V_{10}-V_{11}-D$ and $w_{\mathrm{ns}}=V_{11}-V_{01}-D$.

We can now analyze the initial location choice of the firms.

Proposition 1. Firms choose to locate in the same region if and only if

$$
2 V_{11}-V_{10}-V_{01}>w_{s}=V_{10}-V_{11}-D
$$

Proof. It follows directly from comparing Eqs. (2) and (5).

First notice that the condition for firms to cluster is more stringent than the one driving technology spillovers. Technology spillovers are the only reason to cluster in our model. Therefore, firms would not cluster if technology spillovers could not arise, as a joint location would increase the expected wage of the workers and bring no benefits. ${ }^{14}$

Suppose now that Eq. (3) is satisfied, so technology spillovers can arise when firms cluster. The choice to cluster can be seen as an ex ante agreement to share the knowledge of the first innovation in states where only one firm is successful. Ex post, technology spillovers reduce the profits of the successful firm and increase the profits of the unsuccessful one. However, as Eq. (3) holds, the successful firm loses less than the unsuccessful firm gains, so technology spillovers increase expected joint profits (gross of wages). It follows that technology spillovers also increase ex ante expected profits, since firms are equally likely to end up as the successful or the unsuccessful firm. The cost associated with technology spillovers is the higher expected wage earned by the workers due to the competition in the labor market. Condition (6) thus simply states that firms cluster if and only if the benefits from technology spillovers (the left-hand side of condition (6)) are greater than the additional wage bill (the right hand side of condition (6)).

Proposition 1 shows that stronger trade secret protection, higher $D$, induces firms to cluster in a larger region of the parameter space because the rents captured by the workers are reduced. Stronger trade secret protection is therefore welfare improving because when technology spillovers arise in equilibrium, they increase both industry profits, expected wages of the workers, and competition in the product market.

14 Of course, the firms may cluster for reasons that are not captured in our model; see the discussion in the Introduction. 


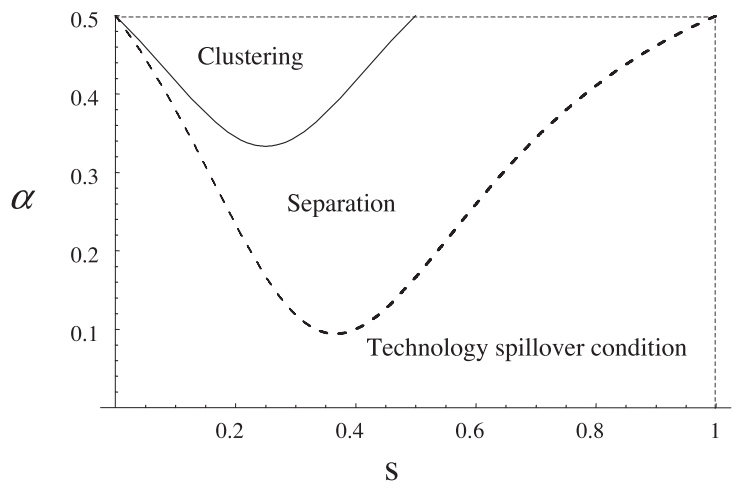

Fig. 4. The equilibrium location of the firms $\left(\pi_{2} / \pi_{1} \quad 3 ; D \quad 0\right)$. Above the solid line, the firms cluster, and below, they locate separately. The dashed line indicates the technology spillover condition.

Corollary 1. An increase in the strength of trade secret protection does not prevent technology spillovers, enlarges the parameter space under which clustering takes place, and is always (weakly) welfare improving.

Two caveats are in place at this point. First, clustering is not necessarily welfare improving once firms' R\&D choices are endogenized, see Section 4.1. Second, if trade secret protection is so strong that it exceeds the value of the worker for the hiring firm, technology spillovers would never occur unless firms privately agree on establishing a reduced level of damage compensation. Presumably, such negotiations are difficult, and firms may not always be able to reach the joint profit maximizing outcome. Thus, very strong trade secret protection may actually be worse than no protection, as it can prevent technology spillovers from arising in situations where all parties involved would benefit from them.

Condition (6), as a function of our exogenous parameters, $\alpha, s$, and $\left(\pi_{2} / \pi_{1}\right)$, is illustrated in Fig. 4. Similarly to condition (3), condition (6) is more likely to be satisfied for high values of $\pi_{2} / \pi_{1}$ and $\alpha$ and for intermediate values of $s$. This suggests that local industrial districts with high levels of labor turnover, like Silicon Valley, are associated with industries (biotechnology, semiconductors) where the prospect of future profits outweighs the importance of actual profits. It is less likely that we observe clustering and high labor mobility in industries with low growth potential. Finally, firms in clustered industries should, ceteris paribus, pay higher wages for the same job. Our model would thus predict a positive correlation between the growth potential of the industry, the geographic concentration of R\&D activities, job mobility, and skilled labor wages.

\section{Extensions}

We consider different extensions of the basic model presented in Section 3. To save space, all proofs have been left out but are available upon request. 


\subsection{Endogenous $R \& D$}

So far, we have not analyzed R\&D decisions explicitly, but have simply assumed that firms are blessed with an exogenous probability to innovate. Here, we discuss how our results change once $R \& D$ is endogenized. Successful $R \& D$ will usually be the result of an investment by the firm and efforts by the workers. For clarity, we consider two polar cases: One where only the firm's investment matters, and another where it is the worker's effort that is crucial. The algebra of the former case can be found in our working paper (Fosfuri and Rønde, 2003).

\subsubsection{R\&D investment by the firm}

We consider a setup where in each period firms choose their own probability to develop an innovation (i.e., their R\&D intensity). The $R \& D$ decision is taken after a worker has been hired. The game remains otherwise unchanged with respect to our basic model in Section 3. We assume that the cost of $\mathrm{R} \& \mathrm{D}$ is quadratic. If firm $z \in\{A, B\}$ chooses a probability $s_{z}$ to innovate, it must incur a cost $\gamma\left(s_{z}\right)^{2} / 2$. The parameter $\gamma$ controls for how costly the R\&D activity is.

Solving backwards, the first step is to compute the equilibrium R\&D intensities in the second period given the knowledge available to the firms. Then, one can derive the corresponding second-period equilibrium profits, $V_{i j}$. As in the basic model, technology spillovers arise if and only if $V_{10}+V_{01}>2 V_{11}$. A closer inspection of this condition shows that the parameter space under which technology spillovers arise expands, roughly speaking, for larger values of $\alpha$ and $\left(\pi_{2} / \pi_{1}\right)$. The parameter $\gamma$ plays a role similar to our exogenous $s$ in Section 3. One can show that the endogenous R\&D intensities are inversely related to $\gamma$. Technology spillovers occur, as the previous analysis would suggest, for intermediate values of $\gamma$ where the equilibrium R\&D intensities also are intermediate. No technology spillovers occur for low (high) values of $\gamma$ where R\&D intensities are high (low).

Moving upwards in the game tree, one can solve for the equilibrium R\&D intensities in the first period. These intensities depend on the location decision and on whether technology spillovers can arise in the second period. When firms cluster in the first period, R\&D intensities can be shown to be increasing with the strength of trade secret protection. Unlike in the basic model, trade secret laws play the important role of stimulating investment in R\&D. Still, one can show that as long as trade secret protection is not excessive (i.e., the equivalent of assumption A.1 holds), first-period R\&D intensities are the highest when firms separate. The reason is that technology spillovers generate a free-riding problem: A firm that was unsuccessful in the first period can (sometimes) hire the rival's worker and acquire the knowledge of innovation 1 in the second period. The possibility of free riding on the rival's investment reduces firms' incentives to invest in R\&D in the first period. ${ }^{15}$

As a last step, one needs to compare the two-period expected profits under clustering and under separation. Again, it turns out that technology spillovers are a necessary but not sufficient condition for clustering and that the conditions favoring technology spillovers also lead to more clustering (high values of $\alpha$ and $\left(\pi_{2} / \pi_{1}\right)$ and intermediate values of $\gamma$ ). Overall, endogenizing the R\&D investment does not invalidate the comparative statics

15 We thank an anonymous referee for suggesting to us this possibility. 
obtained in Section 3. However, our finding that clustering was always welfare improving is not any longer so clear-cut, because first-period $R \& D$ intensities are lower under clustering than under separation. Without specifying in greater details the demand structure and the mode of competition, we cannot undertake a full welfare analysis. It might well be that clustering is still welfare enhancing for all acceptable parameter values, but we cannot be sure of this. ${ }^{16}$ This points out that whereas most of our findings are pretty robust, our conclusion about welfare should be taken with caution.

\subsection{2. $R \& D$ investment by the workers}

The efforts of key researchers are often crucial for R\&D success, and it is in the interest of a firm to provide its researchers with high-powered incentive schemes. Although objective measures of R\&D success, such as patents, publications, and profits, are sometimes available, in most cases, it is difficult to write employment contracts that are contingent on R\&D outcomes. A firm can promise to reward a successful researcher, but such a promise is usually not legally binding. The firm faces then a commitment problem: Ex ante, it is optimal to promise to reward a successful researcher to provide incentives. Ex post, once the innovation has been made, it is tempting for the firm to renege on this promise.

One of the results in Section 3 is that when firms choose to cluster, workers who possess the knowledge of innovation 1 command a higher expected wage in period 2 . Hence, locating in a high-tech cluster could serve as a commitment to reward successful workers and might result in higher $R \& D$ efforts in the first period compared to separation. ${ }^{17}$ In a related work, Motta and Rønde (2002) develop this idea in the context of covenants not to compete. They show that it can be optimal not to include a covenant not to compete in the employment contract to let a successful worker receive outside offers and alleviate the commitment problem described above. Contrary to our previous analysis, this also suggests that when the R\&D efforts of the workers play a crucial role, stronger trade secret protection might result in a lower level of innovation activity, because wages are reduced.

\subsection{No wealth and credit constraints}

The workers earn an expected wage above 0 (the reservation wage) in the second period when firms cluster. The workers would therefore be willing to accept a negative first-period wage as long as they could survive the first period by consuming initial wealth or borrowing on the capital markets. Of course, the expected wage over the two periods must be nonnegative. Suppose that the workers have access to an initial wealth or credit of $w_{0}>0$. Assuming that the total amount of money available for consumption each period should be

\footnotetext{
16 In fact, without specifying these details we do not even know whether firms over or underinvest in R\&D compared to the first-best, since firms' R\&D decisions generate two externalities going in opposite directions. First, firms do not take into account the effect of their own R\&D investment on their competitor's profits. Second, firms ignore the part of the value created by the innovation that accrues to consumers. The first externality pushes towards overinvestment in R\&D and the second towards underinvestment.

17 In our two-period setup, clustering would have no effect on efforts in the second period, because firms only compete for the workers once. Motta and Rønde (2002) study an infinite horizon setup where reputation concerns sometimes solve the commitment problem.
} 
nonnegative, the first-period wage cannot be lower than $-w_{0}$. Solving the game as before, we obtain the following proposition:

Proposition 2. Suppose that $2 V_{11}>V_{10}+V_{01}$, so technology spillovers can arise when firms choose a joint location. For $w_{0}<s(1-s)\left(V_{10}-V_{11}-D\right)$, the firms cluster if and only if

$$
s(1-s)\left[2 V_{11}-\left(V_{10}+V_{01}\right)-\left(V_{10}-V_{11}-D\right)\right]+w_{0} \geq 0 .
$$

For $w_{0} \geq s(1-s)\left(V_{10}-V_{11}-D\right)$, the workers earn no expected rents, and the firms always cluster. If $2 V_{11}<V_{10}+V_{01}$, the firms always (weakly) prefer to locate in separate regions.

We see by comparing Eqs. (6) and (7) that the firms cluster for a larger region of the parameter space when the wealth constraint is relaxed. The negative first-period wage allows the firms to extract (some of) the rents earned by the workers, which makes it more attractive to choose a joint location. ${ }^{18}$

\subsection{Finite relocation costs for workers}

In Section 3, we have assumed that it is prohibitively expensive to hire a worker employed in a different region. Now, we allow for lower levels of relocation costs. Suppose that firm $i$ has to pay a fixed cost $k>0$ when poaching the worker from firm $j$ located in a different region. Here, there are different cases to consider. First, if $2 V_{11} \leq V_{10}+V_{01}$, technology spillovers do not arise independently of $k$ and firms' locations. The firms thus separate, because the relocation costs reduce the wage of the workers. Second, if $2 V_{11}>V_{10}+V_{01}+k$, technology spillovers arise both under clustering and separation. It is optimal to cluster to avoid paying the relocation costs. Finally, the most interesting case happens when $V_{10}+V_{01}<2 V_{11} \leq V_{10}+V_{01}+k$. Here, technology spillovers arise only if firms cluster. We need to distinguish between two subcases. If $k>V_{11}-V_{01}-D$, the lagging firm is not interested in hiring a worker from a firm located in another region. Thus, the analysis developed in Section 3 remains unchanged. On the other hand, if $k<V_{11}-V_{01}-D$, the lagging firm is willing to pay up to $V_{11}-V_{01}-D-k>0$ to attract the worker. The model can then be solved as in Section 3. We obtain that firms cluster if and only if

$$
\begin{aligned}
& 2 V_{11}-\left(V_{10}+V_{01}\right) \geq \underbrace{V_{10}-V_{11}-D}_{\text {wage clustering }\left(w_{\mathrm{s}}\right)}-\frac{\operatorname{Max}\left\{0, V_{11}-V_{01}-D-k\right\}}{\text { wage separation }\left(w_{\mathrm{ns}}\right)} \Leftrightarrow \\
& 2 V_{11}-\left(V_{10}+V_{01}\right) \geq \frac{k}{2} \text { if } k<V_{11}-V_{01}-D, \\
& 2 V_{11}-\left(V_{10}+V_{01}\right) \geq V_{10}-V_{11}-D \text { otherwise. }
\end{aligned}
$$

Notice that for low levels of relocation costs, the protection provided by separate locations is stronger the greater is $k$. Therefore, the profits under separation are increasing in

\footnotetext{
18 This leads to the empirical prediction that workers in a high-tech cluster will have a steeper earnings profile over time than workers outside a cluster.
} 
$k$, which in turn makes clustering less attractive. For high relocation costs, we find again condition (6). Removing the assumption of prohibitively high relocation costs changes the threshold for which firms cluster, but the basic trade-off of the model remains.

\subsection{The knowledge is embedded in the worker}

We now allow for the possibility that the innovating firm experiences a loss of knowledge when the worker moves to a rival. For example, this could be because the employee 'hides' some of the relevant knowledge, or because some of the knowledge is tacit and difficult to articulate. Such a loss of knowledge translates into a lower probability to develop innovation 2 . To capture this possibility, we assume that if the worker leaves, the probability to develop innovation 2 is $\mu s$ with $\mu \leq 1$. The formal analysis remains basically unchanged with respect to Section 3. Suppose that only firm A develops innovation 1. The expected profits of firm $\mathrm{A}$ if it loses the worker are now $V_{11}^{\mathrm{A}}(\mu)=\mu s^{2} \alpha \pi_{2}+\mu s(1-s) \pi_{2}+(1-s)(1-\mu s) \alpha \pi_{1}+D$. Similarly, the expected profits of firm B if it hires the worker are $V_{11}^{\mathrm{B}}(\mu)=\mu s^{2} \alpha \pi_{2}+s(1-\mu s) \pi_{2}+(1-s)(1-\mu s) \alpha \pi_{1}-D$. Following the analysis in Section 3, it is easy to show that technology spillovers only occur if $V_{11}^{\mathrm{A}}(\mu)+V_{11}^{\mathrm{B}}(\mu)>V_{10}+V_{01}$, where $V_{10}$ and $V_{01}$ are given by Eq. (1). Notice that only the left-hand side of the inequality depends on $\mu$. One can show that the derivative of the left-hand side of the inequality with respect to $\mu$ is always positive. This implies that the larger is $\mu$, the larger is the parameter space for which technology spillovers take place. Firms cluster if and only if $V_{11}^{\mathrm{A}}(\mu)+V_{11}^{\mathrm{B}}(\mu)-\left(V_{10}+V_{01}\right)>V_{10}-V_{11}^{\mathrm{A}}(\mu)-D$, and this inequality is laxer for higher values of $\mu$. In other words, when the movement of the worker implies a loss of knowledge for the innovating firm, it is less likely that we observe clustering and technology spillovers. In the limit for $\mu=0$, one can show that technology spillovers never take place. As a result, firms do not cluster. Here, the worker's mobility would simply shift R\&D capabilities from firm A to firm B without increasing the overall probability to develop innovation 2. Furthermore, some profits would be dissipated because both firms would have innovation 1 and compete in the product market. In sum, our results derived in Section 3 rely on knowledge being a public good within the innovating firm.

\subsection{Injunctive relief and covenant not to compete}

Suing for damages is not the only means available to a firm for protecting its trade secrets against misappropriation. For instance, it can seek an injunctive relief when the worker leaves or can include a covenant not to compete in the labor contract. We can model these two options in a similar way by assuming that if an employee with valuable knowledge is hired by a rival firm, there is a probability $p$ that a court will prevent him from working for his new employer. $p$ is either the probability that the court grants injunctive relief or enforces a covenant not to compete. We assume that the new

employer has to pay the wage offered no matter the outcome of a trial. In addition, let $D=0$.

Suppose that firm A has developed the first innovation, but firm B has not. The firms' valuations of the worker are modified as follows: $v_{\mathrm{A}}^{\prime}=(1-p)\left(V_{10}-V_{11}\right)$ and 
$v_{\mathrm{B}}^{\prime}=(1-p)\left(V_{11}-V_{01}\right)$, because firm B can only exploit the knowledge with probability $1-p$. From $v_{\mathrm{A}}^{\prime} \geq(<) v_{\mathrm{B}}^{\prime}$, it follows that labor turnover takes place exactly for the same parameter space that we derived in Section 3. However, when labor turnover occurs, technology spillovers arise only with probability $(1-p)$. Solving the model as before, we obtain that firms cluster if and only if $2 V_{11}-V_{10}-V_{01} \geq V_{10}-V_{11}$. The strength of trade secret protection does not affect firms' ex ante incentives to cluster, because trade secret protection has two effects that cancel exactly out. On the one hand, stronger trade secret protection reduces the wage that workers receive, which, in turn, reduces the costs of clustering. On the other, there are fewer technology spillovers, which reduce the benefits of clustering.

Proposition 3. Post employment covenants not to compete and the possibility to seek an injunctive relief reduce the amount of technology spillovers that arise in a cluster and do not affect firms' incentives to cluster.

A system of trade secret protection based on covenants not to compete or the possibility to seek an injunctive relief behave quite differently from one based on punitive damages. Indeed, stronger protection does not affect clustering. Instead, it prevents technology spillovers from arising when firms locate in the same region. In this sense, our model provides some support to Gilson's (1999) claim that the lack of enforceable covenants not to compete has spurred labor mobility and innovation in Silicon Valley.

\section{Conclusion}

Motivated by the recent debate about the reasons underpinning the success of Silicon Valley, we have studied firms' incentives to cluster in order to benefit from reciprocal technology spillovers. Generally speaking, we find that the story of Silicon Valley, as told by economic geographers and other scholars, is consistent from an economic point of view. Our formal model, however, allows us to pin down the crucial assumptions behind the argument. We find that firms' incentives to cluster are the strongest when the following three conditions are met: (1) the value of later innovations is high relative to earlier ones; (2) competition in the product market is relatively soft; (3) the probability of a single firm to develop an innovation is neither very high nor very low. Especially, the first condition is important for empirical research. It suggests that clustering and technology spillovers are more likely to be observed in industries with high growth potential. Hence, a standard OLS regression aimed at quantifying the benefits of clustering and technology spillovers on firms' profitability might produce biased estimates, if it does not control for this characteristic. This finding also warns policy makers against the attempt of trying to "clone" the success of Silicon Valley in industries that have structurally much smaller growth potential.

In addition, our model predicts that in industries where clustering is driven by technology spillovers, labor turnover is high and skilled workers receive, ceteris paribus, higher wages. These findings seem to fit well with the stories of industries such as semiconductors and biotechnology (Zucker and Darby, 1996; Almeida and Kogut, 1999). 
Interesting enough, our model also suggests that weak trade secret protection might not be a prerequisite for clustering and labor mobility as some legal scholars have recently argued. Indeed, we show that a system of trade secret protection based on punitive damages, except in some extreme cases, is beneficial for firms' profits, stimulates clustering, and is not an impediment to workers' mobility. However, trade secret protection that prevents technology spillovers from arising (post-employment covenants not to compete, injunctive relief, or excessive damages) does not affect clustering. Instead, profits are reduced because, although firms have clustered, technology spillovers do not materialize.

\section{Acknowledgements}

We would like to thank A. Gambardella, M. Motta, A.L. Saxenian, K.O. Stahl, two anonymous referees, and participants at seminars at Sant'Anna School of Advanced Studies (Pisa), The Third Economic Geography of Europe Conference (Villars) and University Pompeu Fabra (Barcelona) for helpful comments and suggestions on an earlier draft. Andrea Fosfuri gratefully acknowledges financial support from the Spanish Ministry of Science and Technology (SEC2000-0395) and from the European Commission Key Action "Improving the socio-economic knowledge base" (HPSE-CT-2002-00146). Thomas Rønde gratefully acknowledges financial support from the European Commission under the TMR network "The Evolution of Market Structure in Network Industries" (FMRXCT98-0203) and under the RTN Network "The Economic Geography of Europe: Measurement, Testing and Policy Simulations" (HPRN-CT-2000-00069). Part of this work was done when Thomas Rønde was visiting LEFIC at Copenhagen Business School, and he gratefully acknowledges the hospitality of this center.

\section{References}

Acs, Z.J., Audretsch, D.B., Feldman, M.P., 1994. R\&D spillovers and recipient firm size. Review of Economics and Statistics 76, 336340 .

Almeida, P., Kogut, B., 1999. Localization of knowledge and the mobility of engineers in regional networks. Management Science 45, 905916.

Arrow, K., 1962. Economic welfare and the allocation of resources for inventions. In: Nelson, R. (Ed.), The Rate and Direction of Inventive Activity: Economic and Social Factors. Princeton Univ. Press, Princeton, NJ.

Audretsch, D.B., 1998. Agglomeration and the location of economic activity. CEPR Discussion Paper Series 1974.

Audretsch, D.B., Feldman, M., 1996. R\&D spillovers and the geography of innovation and production. American Economic Review 86, 630640.

Bessen, J., Maskin, E., 2000, Sequential Innovation, Patents, and Imitation. WP 00-01, Harvard University and MIT.

Budden, M.C., 1996. Protecting Trade Secrets Under the Uniform Trade Secrets Act. Quorum Books, Westport, CT.

Cheung, S.N.S., 1982. Property rights in trade secrets. Economic Inquiry 20, 4053.

Choate, R.A., Francis, W.H., Collins, R.C., 1987. Cases and Materials on Patent Law, 3rd ed. West Publishing, St. Paul.

Choi, J.P., 1993. Cooperative R\&D with product market competition. International Journal of Industrial Organization 11,553571 . 
Combes, P.P., Duranton, G., 2001. Labour pooling, labour poaching, and spatial clustering. CEPR Discussion Paper Series 2975.

Cooper, D.P., 2001. Innovation and reciprocal externalities: information transmission via job mobility. Journal of Economic Behavior and Organization 45, 403425.

Fosfuri, A., Rønde, T., 2003. High-tech clusters, technology spillovers, and trade secret laws. CIE Discussion Paper 2003-02. Available at http://www.econ.ku.dk/CIE/.

Fosfuri, A., Motta, M., Rønde, T., 2001. Foreign direct investments and spillovers through workers' mobility. Journal of International Economics 53, 205222.

Gersbach, H., Schmutzler, A., 2003. Endogenous spillovers and incentives to innovate. Economic Theory 21, 5979.

Gilson, R.J., 1999. The legal infrastructure of high technology industrial districts: Silicon Valley, Route 128, and coventants not to compete. New York University Law Review 74, 575629.

Hyde, A., 2001, The wealth of shared information: Silicon Valley's high velocity labor market, endogenous economic growth and the law of trade secrets. Unpublished manuscript, Rutgers University.

Jaffe, A., Trajtenberg, M., Henderson, R., 1993. Geographic localization of knowledge spillovers as evidenced by patent citations. Quarterly Journal of Economics 108, 577598.

Joung Yeo, A., 2002, Agglomeration Effects in the Diffusion of Advanced Manufacturing Technologies. Unpublished manuscript, University of Toronto, Canada.

Kamien, M.I., Muller, E., Zhang, I., 1992. Research joint ventures and R\&D cartels. American Economic Review 82, 12931306.

Katz, M.L., 1986. An analysis of cooperative research and development. RAND Journal of Economics 17, 527543.

Krugman, P.R., 1991a. Geography and Trade. The MIT Press, Cambridge, MA.

Krugman, P.R., 1991b. Increasing returns and economic geography. Journal of Political Economy 99, 484499.

Mai, C.C., Peng, S.K., 1999. Cooperation vs. competition in a spatial model. Regional Science and Urban Economics 29, 463472.

Marshall, A., 1920. Principles of Economics, 8th ed. MacMillan, London.

Motta, M., Rønde, T., 2002. Trade secret laws, labor mobility, and innovations. CEPR Discussion Paper Series 3615 .

Pakes, A., Nitzan, S., 1983. Optimum contracts for research personnel, research employment, and the establishment of 'rival' enterprises. Journal of Labor Economics 1, 345365.

Rajan, R.G., Zingales, L., 2001. The firm as a dedicated hierarchy. Quarterly Journal of Economics 116, 805851.

Rønde, T., 2001. Trade secrets and information sharing. Journal of Economics and Management Strategy 10, 391417.

Saxenian, A., 1994. Regional Advantage: Culture and Competition in Silicon Valley and Route 128. Harvard Univ. Press, Cambridge, MA.

Scotchmer, S., 1991. Standing on the shoulders of giants: cumulative research and the patent law. Journal of Economic Perspectives 5, 2941.

Stigler, G., 1951. The division of labour is limited by the extent of the market. Journal of Political Economy 59, 185193.

Zabojnik, J., 2002. A theory of trade secrets in firms. International Economic Review 43, 831855.

Zucker, L., Darby, M., 1996. Star scientists and institutional transformation: patterns of invention and innovation in the formation of biotechnology industry. Proceedings of the National Academy of Science of the United States of America 93, 709716.

Zucker, L., Darby, M., Brewer, M., 1998. Intellectual human capital and the birth of U.S. Biotechnology Enterprises. American Economic Review 88, 290306. 